Revista "Política y Estrategia" № 135, 2020, pp. 73-98

ISSN 0716-7415 (versión impresa) - ISSN 0719-8027 (versión en línea)

Academia Nacional de Estudios Políticos y Estratégicos

La Defensa: En el dilema del zorro y el erizo

Fulvio Queirolo Pellerano

\title{
LA DEFENSA: EN EL DILEMA DEL ZORRO Y EL ERIZO• $\infty$
}

\section{FULVIO QUEIROLO PELLERANO*}

\begin{abstract}
"En América Latina, sin embargo, una evaluación comparable es imposible de hacer, ya que no se han estipulado normas externas, y mucho menos institucionalizadas internamente. Los incentivos de zanahoria y palo que se encuentran en Europa faltan en América Latina. El atlas RESDAL, por ejemplo, lo aclara por su virtual falta de atención a la supervisión, educación profesional y estrategia"1.
\end{abstract}

\section{RESUMEN}

En el ejercicio de actualizar los cometidos que debería asumir la Defensa estatal en un entorno global, regional y local pos Guerra Fría, se ha reconocido que las dinámicas de incertidumbre, también, modificaron las tradicionales nociones sobre riesgos y amenazas. Este entorno ha situado a la estructura de la Defensa como objeto principal de estudio y así validar sus roles y funciones. Sin embargo, es posible advertir que, durante la tarea de evaluar el comportamiento de las FF.AA. Latinoamericanas en democracia, se habría incurrido en sesgos que han distorsionado el resultado. Este ensayo, desarrollado como parte del programa del Doctorado en Seguridad Internacional de la Universidad Nacional de Educación a Distancia pretende revelar la forma en que dichos criterios afectaron algunos trabajos que, tomando

× Fecha de recepción: 010520 - Fecha de aceptación: 130820..

- "The Hedgehog and the Fox", tomado de la fábula de Esopo, que fue conocida a través del ensayo de Sir Isaiah Berlin (1953) sobre León Tolstoi, y más tarde Thomas Bruneau (2005), utiliza para analizar las relaciones civiles-militares en Latinoamérica: "El zorro sabe muchas cosas, pero el erizo sabe una gran cosa". Esto sugiere que, "El zorro, pese a su astucia, es derrotado por la defensa del erizo. En este caso, el zorro, representa a los políticos y gobiernos que debiesen saber muchas cosas, mientras que las Fuerzas Armadas son como el erizo, porque saben una gran cosa: seguridad nacional y defensa.

* Magíster en "Ciencia política, seguridad y defensa" de la Academia Nacional de Estudios Políticos y Estratégicos (ANEPE); Magíster en "Ciencias Militares con mención en Planificación y Gestión Estratégica" (ACAGUE). Fue Observador Militar en la misión de Naciones Unidas UNTSO, en Medio Oriente (2003/2004); luego Jefe de Departamento de Logística en Haití, MINUSTAH (2007/2008) y, finalmente, Agregado Militar de Chile en Israel (2013/2015). Editor de revista "Mirador Mundial" y "Panorama de Seguridad y Defensa" en ANEPE. Se encuentra Doctorando en programa de "Seguridad Internacional" en la Universidad Nacional de Educación a Distancia (UNED). En la actualidad es Jefe de Estudios Estratégicos del CIEE-ANEPE. fqueirolo@anepe.cl ORCID: https://orcid.org/0000-0001-6837-0962

1 BRUNEAU, Thomas C. "Civilians and the Military in Latin America: The Absence of Incentives". En: "Latin American Politics and Society", october 2013. pp. 143-160. [en línea] [fecha de consulta 16 de junio 2020] Disponible en: <https://www.cambridge.org/core/journals/latin-american-politics-and-society/article/civilians-and-the-military-in-latin-america-the-absence-of-incentives/4827EF488F205B76318692CC3C351A99>. 
como perspectiva las relaciones civiles-militares, intentan validar las variables "democrático control civil, efectividad y eficiencia" como principal fuente de dificultades para avanzar en su evolución.

Comprendiendo la dificultad para emprender un estudio que responda de manera cabal el postulado, se ha optado por el empleo de una metodología cualitativa de tipo descriptiva y exploratoria facilitando la obtención e interpretación de información extraída de trabajos publicados y previamente seleccionados por el autor. Luego se aplicará un proceso de análisis de datos buscando sintetizar los antecedentes obtenidos, y evaluados por especialistas en el área, procurando presentar como resultado aquellos elementos relevantes que confirmen las desviaciones y permitan incentivar futuras investigaciones.

Palabras clave: Defensa; seguridad; Fuerzas Armadas; sociedad; control democrático.

\title{
DEFENSE: IN THE FOX AND HEDGEHOG DILEMMA
}

\begin{abstract}
In the exercise of updating the tasks that the State Defense should assume in a post-Cold War regional and local environment, it has been recognized that the dynamics of uncertainty, also, modified the traditional notions of risks and threats. This environment has placed the Defense structure as the main object of study and thus validates its roles and functions. However, it is possible to notice that during the task of evaluating the behavior of the Latin American Armed Forces, in a democracy; biases would have been incurred that have distorted the result.

This essay, developed as part of the Doctorate program in International Security of the National University of Distance Education tries to reveal the way in which said criteria affected some works that, taking civil-military relations as a perspective, try to validate the variables "democratic civil control, effectiveness and efficiency" as the main source of difficulties to advance their evolution

Understanding the difficulty of undertaking a study that fully answers the postulate, we have opted for the use of a descriptive and exploratory qualitative methodology, facilitating the obtaining and interpretation of information extracted from published works previously selected by the author. Then, a process of data analysis will be applied, seeking to synthesize the antecedents obtained and evaluated by specialists in the area, aiming to present as a result those relevant elements that confirm the deviations and allow incentives for future research
\end{abstract}

Key words: Defense; security; Armed Forces; society; democratic control. 
La Defensa: en el dilema del zorro y el erizo

\title{
A DEFESA: NO DILEMA DA RAPOSA E DO OURIÇO
}

\begin{abstract}
RESUMO
No exercício de atualizar as tarefas que a Defesa do Estado deveria assumir em um ambiente global, regional e local pós-Guerra Fria, reconheceu-se que a dinâmica da incerteza também modificou as noções tradicionais sobre riscos e ameaças. Esse ambiente colocou a estrutura de Defesa como principal objeto de estudo e, assim, valida seus papéis e funções. No entanto, é possível notar que, durante a tarefa de avaliar o comportamento das Forças Armadas. As mulheres latino-americanas em uma democracia teriam sofrido vieses que distorceram o resultado. Este ensaio, desenvolvido como parte do programa de Doutorado em Segurança Internacional da Universidade Nacional de Educação a Distância procura revelar a maneira como esses critérios afetaram alguns trabalhos que, considerando as relações civilmilitares, tentam validar as variáveis "controle civil democrático, eficácia e eficiência" como principal fonte de dificuldades para avançar em sua evolução.

Entendendo a dificuldade de se realizar um estudo que responda plenamente ao postulado, optamos pelo uso de uma metodologia qualitativa descritiva e exploratória, facilitando a obtenção e interpretação de informações extraídas de trabalhos publicados previamente selecionados pelo autor. Em seguida, será aplicado um processo de análise dos dados, buscando sintetizar os antecedentes obtidos e avaliados por especialistas da área, procurando apresentar como resultado os elementos relevantes que confirmam os desvios e permitem incentivos para futuras pesquisas.
\end{abstract}

Palavras-chave: Defesa; segurança; Forças Armadas; sociedade; controle democrático.

\section{Introducción}

Para nadie podría resultar desconocido el consentimiento establecido por la Organización de Estados Americanos (OEA) para definir "nuevas amenazas" conceptualizadas en la Declaración de Seguridad para las Américas, suscrita en ciudad de México en octubre del 2003. Partiendo desde esta hipótesis, también se podría sostener que dicha proclamación rubricó el destino de políticas que han influido en el sector Defensa desde su anuencia y, en particular, durante la última década.

Una de las fórmulas que se ha incoado en el espacio público latinoamericano ha sido lograr un efectivo "control democrático" de las estructuras superiores de la Defensa, entendiendo que la situación mundial y regional mutó de viejas conceptualizaciones de seguridad diseñadas para épocas de Guerra Fría hacia otro escenario, esta vez anulando tradicionales hipótesis de conflicto. 
En efecto, la caída del Muro de Berlín marcó el inicio de una afanosa carrera por actualizar contenidos y alcances de las funciones de Seguridad y Defensa estatal. Una de las contribuciones más connotadas ha sido la proporcionada por investigadores de la Escuela de Copenhague ${ }^{2}$, quienes desde los "complejos de seguridad" pregonaron para evitar una securitización de todos los problemas ajenos al conflicto y que aquejaban al Estado. Otras visiones más actuales avanzaron hacia un modelo de Reforma al Sistema de Seguridad (SSR por sus siglas en inglés), siendo asumido por el Centro de Ginebra para el Control Democrático de las FF.AA. (DCAF), cuyo énfasis se ha posesionado en la "seguridad humana" y el rol del Estado en la manera de comprender la seguridad nacional, alejándola de ideologías o doctrinas ${ }^{3}$.

En esta compleja trama de redefiniciones de roles, funciones y responsabilidades de la Defensa y sus estructuras, Bruneau ${ }^{4}$ confiere en sincronizar una "trinidad" de tareas estatales que deberían materializarse durante el ejercicio del poder civil y, aplicando un modelo que se aproxima alSSR-DCAF, establece tres niveles de acción: el primero de ellos es alcanzar un "democrático control civil"; el segundo, evaluar la "efectividad" y, finalmente, medir la "eficiencia". Logrado lo anterior se podrían prescribir "legados no democráticos" que aún, según su axioma, se mantendrían en Latinoamérica. De esta manera, la fábula del "Zorro y el Erizo" ${ }^{5}$ se ajusta a su filosofía y recurre a ella para ilustrar su tesis.

Este entorno, para el Consejo de Defensa Suramericano (CDS), con patrocinio de UNASUR ${ }^{6}$, contribuyó, en nuestra opinión, en cimentar una noción artificial de seguridad al postular, para el Continente Americano, como "Zona de Paz". En este escenario, se intenta restringir el avance en materias de Defensa, y como consecuencia natural de esta condición las estructuras de Defensa deberían sintonizarse con este principio, aunque la realidad democrática del cuadro $N^{\circ} 1$ refleja otra categoría, la que aún no recoge lo que se concibe como nuevas amenazas.

Jorge Battaglino7, para destrabar la discusión y contribuir con respuestas más acordes a la realidad sudamericana, formula una nueva conceptualización y la describe como "zona híbrida". De esta forma intenta dar cabida al reconocimiento implícito de temas aún pendientes y que pueden generar una crisis que conlleve la posibilidad del

2 BUZAN, B., WAEVER, O., DE WILDE, O. Security: A new framework for analysis, Boulder, Lynne Rienner Publisher, 1998.

3 SHORT, Clare. Citada por Mark Sedra en: "Security Sector Reform 101". CIGI. April 2010, p.3. Disponible en: https://www.cigionline.org/sites/default/files/ssr 101 final april 27.pdf

4 BRUNEAU, Thomas C. y GOETZE, Richard B. "Las relaciones civil-militares en Latinoamérica". En: "Military Review", Sep-Oct. 2006. pp. 20-28.

5 BRUNEAU, Thomas C. "Civil-Military Relations in Latin America: The Hedgehog and the Fox Revisited". Revista Fuerzas Armadas y Sociedad, Año 19, № 1-2, 2005, pp. 111-131.

6 UNASUR. La Unión de Naciones Suramericanas se define como una comunidad política y económica entre doce países suramericanos (Argentina, Bolivia, Brasil, Chile, Colombia, Ecuador, Guyana, Paraguay, Perú, Surinam, Uruguay y Venezuela), concebida el 8 de diciembre de 2004. A partir del 2018, se convierte en un organismo testimonial luego de la retirada de seis Estados miembro (Argentina, Brasil, Chile, Colombia, Paraguay y Perú).

7 BATTAGLINO, Jorge. "La evolución de la zona de paz sudamericana". Serie de documentos de trabajo N 12, Escuela de Defensa Nacional. Buenos Aires, Argentina, 2012. Disponible En: https://www.academia. edu/5778755/La evoluci\%C3\%B3n de la zona de paz sudamericana 
uso de la fuerza. Si bien se puede compartir con esta noción, daremos cuenta que en los hechos no se avanzó mucho y perduró el primer principio.

\section{Cuadro $\mathbf{N}^{\circ} 1$}

Participación de FF.AA. en golpes de Estado, tensiones internas graves y/o conflictos/ crisis internacionales (1990-2019)

\begin{tabular}{|c|c|c|c|c|c|c|c|c|c|c|c|c|c|c|c|}
\hline \multirow{2}{*}{$\begin{array}{l}\text { Período } \\
\text { Países }\end{array}$} & \multicolumn{3}{|c|}{$1990-95$} & \multicolumn{3}{|c|}{$1996-2001$} & \multicolumn{3}{|c|}{$2002-2007$} & \multicolumn{3}{|c|}{$2008-2013$} & \multicolumn{3}{|c|}{$2014-2019$} \\
\hline & GE & $\mathrm{TI}$ & $\mathrm{CC}$ & GE & $\mathrm{TI}$ & $\mathrm{CC}$ & GE & TI & $\mathrm{CC}$ & GE & TI & $\mathrm{CC}$ & GE & TI & $\mathrm{CC}$ \\
\hline \multicolumn{16}{|l|}{ Argentina (*) } \\
\hline \multicolumn{16}{|l|}{ Brasil (*) } \\
\hline \multicolumn{16}{|l|}{ Bolivia (*) } \\
\hline \multicolumn{16}{|l|}{ Colombia (*) } \\
\hline \multicolumn{16}{|l|}{ Chile $(*)$} \\
\hline \multicolumn{16}{|l|}{ Ecuador $(*)$} \\
\hline \multicolumn{16}{|l|}{ Paraguay } \\
\hline \multicolumn{16}{|l|}{ Perú (*) } \\
\hline \multicolumn{16}{|l|}{ Surinam } \\
\hline \multicolumn{16}{|l|}{ Uruguay } \\
\hline \multicolumn{16}{|l|}{ Venezuela $(*)$} \\
\hline Nota & \multicolumn{7}{|c|}{$\begin{array}{l}\text { Golpes de Estado } \\
\text { Tensión Interna } \\
\text { Crisis/Conflicto Internacional }\end{array}$} & & & & & & & & \\
\hline
\end{tabular}

Nota $(*)$ : Algunas tensiones internas se manifestaron como ejercicios de acuartelamiento de contingentes como símbolo de "malestar" de las FF.AA. por situaciones de política interna, y otras finalizaron con la renuncia de primeros mandatarios.

Fuente: Elaboración propia utilizando antecedentes de Francisco Rojas y fuentes abiertas. En: Memorias del Seminario “Modernización de los Ministerios de Defensa”. Quito, 19-20 de noviembre, 2009. p.11.

https://www.academia.edu/3843447/Memorias del Seminario Modernizaci\%C3\%B3n de los Ministerios de Defensa

Un apasionado Delmas trató de advertirnos sobre este romántico paisaje idealista que se formula en distintos ámbitos, aseverando que el fenómeno de beligerancia no sería producto del poder de los Estados, sino justamente su fragilidad, es decir, provocado por las vulnerabilidades que no han podido gestionar. De esta manera, concluye que el primer efecto de la utopía de la sociedad civil pos Guerra Fría ha sido anunciar la extinción progresiva de la guerra ${ }^{8}$. Así las cosas, habría que preguntarse ¿Cuál realidad sería la más acertada para la región, la del zorro o la del erizo?

La experiencia del ejercicio reformador en estas materias nos enseña que no ha logrado madurar ni menos cosechar los frutos que se perseguían, toda vez que al rediseñar y remodelar las estructuras de Defensa, siguiendo parámetros de "des-securitización" o

8 DELMAS, Filippe. "El Brillante Porvenir de la Guerra”. Editorial Andrés Bello. Santiago, 1996. pp. 21 y 253. 
bien el modelo SSR-DCAF propuesto, se patrocinó una noción de seguridad internacional alejada del propósito por el cual un Estado pregona (seguridad-defensa-desarrollo). Este argumento, paulatinamente, habría marginado al sector Defensa latinoamericano de una virtuosa discusión sobre una necesaria y urgente modernización, que incluye preferentemente al "Zorro y Erizo".

No extraña constatar la abrumadora evidencia de vectores que están incidiendo, progresivamente, en el replanteamiento de las nociones de seguridad, así la dimensión cibernética, la inteligencia artificial, el dominio espacial, las guerras híbridas ${ }^{9}$, el cambio climático y las pandemias, son fenómenos que estarían superando la acción preventiva del Estado, recurriendo periódicamente a los medios de la Defensa, como herramienta multipropósito, asumiendo que dichos instrumentos cuentan con capacidades previamente desarrolladas. El cuestionamiento es si ocurre precisamente lo contrario, tal como Arteaga y Fojón ${ }^{10}$ nos advierten y las administraciones solo intentan reaccionar durante la gestión de una crisis que no han podido prevenir. En esta situación, hablar de "eficiencia y eficacia" en el cometido no aplicaría, solo habría que esperar para evaluar sus resultados, los que probablemente serán muy gravosos.

En un ensayo de gobernabilidad del sector Defensa se presentaron los primeros indicios de "supuestos erróneos" que, a modo de variables, se han utilizado en algunas investigaciones para evaluar roles y funciones de las FF.AA. En trabajos de dicha naturaleza, y utilizando la perspectiva de las relaciones civiles-militares, se aborda un análisis crítico con características de anclaje o amarre a situaciones del pasado transformándose, según nuestra delimitación, en "sesgo cognitivo"11 que ha condicionado la misma trinidad que Bruneau ${ }^{12}$ y otros autores sostienen.

Pion-Berlin reflexionando sobre el poco avance en materias político-estratégicas realiza una dura crítica al estamento político y de esta manera se puede sostener que imputa al "Zorro" por la laxitud que ha exhibido en décadas, actitud que se agudiza por el grado de desconocimiento y condición de abandono reflejado hacia el "Erizo", circunscribiendo un actuar pusilánime mediante supuestas "verdades reveladas" y que cada cierto tiempo ha sido transcritas en los conocidos Libros Blancos ${ }^{13}$.

9 HOFFMANN, R. "Conflict in the 21st Century: The Rise of Hybrid Wars". 2007. p. 14. Disponible en: https:// www.potomacinstitute.org/images/stories/publications/potomac hybridwar 0108.pdf

10 ARTEAGA, F. y FOJÓN, E. "El Planeamiento de la Política de Defensa y Seguridad de España”. Instituto Universitario “General Gutiérrez Mellado" (UNED), Madrid, 2007. p. 23.

11 KAHNEMAN, Daniel. "Pensar Rápido, Pensar Despacio". Le Libros. 2012. pp. 198 - 254; 418 - 437. Disponible en: < https://catedradatos.com.ar/media/kahneman pensar.pdf >.

12 QUEIROLO, Fulvio. Fundamentos para fortalecer la Gobernabilidad. En: “Política y Estrategia” (132), 2018, pp. 161-181.

13 Libros Blancos fue el resultado de los acuerdos sobre medidas de confianza mutua en el marco de la Conferencia de Helsinki 1975, fueron impulsados por la Comisión de Seguridad Hemisférica de la OEA constituyendo una medida de fomento de la confianza mutua entre los países de la región. Últimamente, se han transformado en textos de difusión y orientación estatal sobre temas de seguridad y defensa. En: Libros Blancos de Defensa en Sudamérica: ¿Política exterior o política doméstica? En: "Revista Brasileira de Estudios de Defesa", Vol. 4, N ², julho/dezembro, 2017. P. 17. Disponible en: <https://rbed.abedef. org/rbed/issue/viewFile/2977/410>. 
Admitamos que dichos libros, objetivamente, no abordan ni abarcan en plenitud los nuevos escenarios, ni menos allanan la interdependencia del sector político con el estratégico, justamente porque fueron concebidos con sesgos propios de la Guerra Fría -mirada de amigo-enemigo- conteniendo muchas reflexiones y discreta profundidad en temas de Defensa; incluso si se intercambiaran y editaran en distintos países servirían para el mismo propósito, aun sin importar su autoría ${ }^{14}$, de allí la crítica de sus detractores.

Lo sorprendente para la región es que se continuó avanzando en Libros Blancos o bien textos derivados de Seguridad y/o Defensa de manera más voluntariosa que efectiva (cuadro $\mathrm{N}^{\circ} 2$ ), manteniendo una filosofía marcada por un amalgamado regionalismo ideológico por sobre sus preocupaciones de riesgos y amenazas estatales. La consecuencia es la constreñida respuesta sobre qué se desea hacer y con qué instrumentos se debería enfrentar los nuevos retos, fórmula que aún es muy difícil encontrar en los textos que se mencionan.

\section{Cuadro $\mathrm{N}^{\circ} 2$}

Resumen de publicaciones de Libros Blancos y otros documentos de Defensa en Suramérica (período 1995-2018)

\begin{tabular}{|l|l|c|}
\hline \multicolumn{1}{|c|}{ País } & \multicolumn{1}{|c|}{ Tipo de documento } & Año \\
\hline \hline Argentina & Libro Blanco de la República Argentina & 1999 \\
& & 2010 \\
& & 2015 \\
& Directiva de Política de Defensa Nacional & 2018 \\
\hline Bolivia & Libro Blanco de Defensa Bolivia & 2004 \\
\hline Brasil & Política de Defensa Nacional & 1996 \\
& Política de Defensa & 2005 \\
& Estrategia Nacional de Defensa & 2008 \\
& Libro Blanco de Defensa & 2012 \\
& Libro Blanco de Defensa & 2017 \\
\hline Colombia & Política de Defensa y Seguridad Democrática & 2003 \\
& Política de Defensa y Seguridad para la Nueva Colombia 2015-18 & 2015 \\
\hline Chile & Libro de la Defensa Nacional & 1997 \\
& & 2002 \\
\hline
\end{tabular}

14 PION-BERLIN, David. "Political management of the military in Latin America". En: "Military Review", 2005. pp. 19-31. 


\begin{tabular}{|l|l|c|}
\hline Ecuador & Libro Blanco de la Defensa Nacional & 2002 \\
& Libro Blanco de Defensa & 2006 \\
& Hacia una Nueva Política de Seguridad Interna y Externa & 2008 \\
& Agenda Política de Defensa & 2011 \\
& Agenda Política de la Defensa 2014-17 & 2014 \\
\hline Paraguay & Plan Global del MDN y Política de Defensa Nacional & 1999 \\
\hline Perú & Libro Blanco de la Defensa Nacional del Perú & 2005 \\
\hline Uruguay & Bases para una Política de Defensa Nacional & 1999 \\
& La Defensa Nacional, bases para un debate & 2005 \\
\hline Surinam & Política de Defensa Nacional & 2014 \\
\hline Venezuela & Plan anual del Ministerio de Defensa & 2012 \\
\hline
\end{tabular}

Fuente: Elaboración propia basado en trabajo de Juan González Guyer. Véase en: "Revista Brasileira de Estudios de Defesa". Vol. 4, n², 2017. p. 29. En: https://rbed.abedef.org/rbed/issue/viewFile/2977/410

Resulta apropiado, en esta parte del análisis, reconocer la irrupción de modernas aproximaciones académicas que han avanzado en una redefinición del "control civil" impulsando la conceptualización de un nuevo "liderazgo civil o estratégico" del sector Defensa ${ }^{15}$. En esta línea García Covarrubias establece la conveniencia de contar con un "sistema de liderazgo estratégico", considerando las complejidades que acarrea la conducción de la Defensa y, particularmente, de las FF.AA. De esta manera, la importancia de contar con una adecuada comprensión de lo que significa ejercer el liderazgo civil allanaría la relación entre las autoridades políticas y militares.

Con todo, las bases de esta nueva aproximación se fundan en el conocimiento, confianza, respeto, obediencia, transparencia y experiencia de los actores, elementos constitutivos que requieren de tiempo para su consolidación; sin embargo, la contingencia político-social, muchas veces, modifica las prioridades de las autoridades trasfiriendo efectos contradictorios para la Defensa y que repararemos más adelante.

\section{Redefiniendo la condición de "seguridad"}

A la Declaración de Seguridad de la OEA 2003 se suma la Resolución de la Organización de Naciones Unidas (ONU-2004), colectividad que en su quincuagésimo noveno período de sesiones actualiza la noción de seguridad a la luz de dinámicas conflictivas que estaban sucediendo en diferentes partes del mundo. De esta manera, a modo de orientaciones, se manifiesta sobre el rol que deberían cumplir diversos actores (estatales, institucionales y organismos internacionales), para enfrentar nuevos desafíos “...las amenazas actuales no

15 GARCÍA, C. Jaime. Liderazgo Estratégico en Defensa. En: "Security and Defense Studies Review", Vol. 12, $N^{\circ} 1 \& 2,2011$, pp. $119-134$. Disponible en:

< https://www.hsdl.org/?view\&did=755047 >. 
La Defensa: en el dilema del zorro y el erizo

respetan las fronteras nacionales, están relacionadas entre sí, y deben encararse tanto en los planos mundial y regional como en el plano nacional. Ningún Estado, por más poderoso que sea, puede hacerse invulnerable, por sí solo, a las amenazas actuales. ${ }^{16}$, con una clara invocación a la seguridad colectiva.

Admitamos que, en diferentes trabajos y estudios elaborados por investigadores y centros de estudio regionales, ha sido común y reiterativo encontrar hallazgos que advierten sobre amenazas "nuevas" y, otras, no tan nuevas, a las cuales habría que poner especial atención, antes de que se trasformen en agentes desestabilizadores. Entre estos se recoge la apreciación descrita por Griffiths ${ }^{17}$, en el sentido que ellas mantienen plena vigencia y que probablemente habrá que seguir nutriendo acorde a cada realidad local (cuadro $\mathrm{N}^{\circ}$ 3), considerando que como fenómenos sociales pueden presentar transformaciones que alteran las pautas estatales preestablecidas:

\section{Cuadro $\mathrm{N}^{\circ} 3$ \\ Resumen de fenómenos de seguridad, desde los cuales se generan amenazas en la región Latinoamericana}

\begin{tabular}{|l|l|}
\hline - Disputas fronterizas & - Pobreza \\
- Terrorismo & - Enfermedades infecto contagiosas \\
- Narcotráfico & - Migraciones masivas \\
- Tráfico organizado armas & - Daño al medio ambiente \\
- Movimientos guerrilleros & - Bandas armadas \\
- Armas químicas y biológicas & \\
\hline
\end{tabular}

Fuente: Elaboración propia, basado en trabajo de Griffiths.

Otro investigador que ha avanzado en la redefinición de los entornos y nociones de seguridad regional ha sido Bartolomé ${ }^{18}$, precisando el carácter "transnacional" que manifiestan dichas amenazas, entorno que implica el llamado a la responsabilidad común o colectiva, considerando las limitaciones que posee cada Estado para identificar el origen de ellas y sus alcances.

En este punto del análisis resulta oportuno dedicar unas líneas para reflexionar sobre las orientaciones que "a modo de guía" ha advertido UNASUR-CDS -mientras estaba en funciones- destacando aquella que circunscribe a la región americana como una zona libre de conflictos. Un escenario así supone una clara señal respecto de los modos y modelos estratégicos que debiesen estructurarse para el empleo de los medios de la Defensa y, principalmente, la organización de estos instrumentos. Nuevamente la

16 ONU. Resolución A/59/565. Asamblea General 2 de diciembre de 2004. pp.11-15. Disponible en: $\leq$ https:// www2.ohchr.org/spanish/bodies/hrcouncil/docs/gaA.59.565 Sp.pdf. >.

17 GRIFFITHS, S., John. Cap. II "Análisis General de la Evolución Conceptual de las Nociones de Seguridad y Defensa en el Continente Americano durante el Período de Post Guerra Fría 1990-2006". En: Teoría de la Seguridad y Defensa en el Continente Americano. Análisis de los casos de EE.UU. de América, Perú y Chile. RIL Editores, 2011. pp. 125 - 219.

18 BARTOLOMÉ, Mariano C. "La Seguridad Internacional en el Siglo XXI, más allá de Westfalia y Clausewitz". En: “Colección Investigaciones”, ANEPE N¹4, septiembre 2006. p. 21. 
pregunta ¿Para qué tipo de conflictos debiese prepararse la región, los que considera deseable el zorro o posibles el erizo? La respuesta no supera el dilema propuesto en el ensayo y se hace engorroso encontrar soluciones globales para ser aplicadas de manera particular. En consecuencia, la variable "libre de conflictos" sería un sesgo levantado desde los estudios seleccionados, ya que ancla al fenómeno del conflicto en un escenario bélico entre Estados, cuestión que debió ser despejada luego de la Declaración de México 2003.

Una posible respuesta podría hallarse en el análisis del entorno estratégico internacional que se refleja en el trabajo llevado a cabo por investigadores de la Academia Nacional de Estudios Políticos y Estratégicos (ANEPE), quienes, situándose en la teoría de las relaciones internacionales y apoyados en disciplinas como historia, ciencias sociales, ciencias militares, sociología y ciencia política documentan la manera en que paulatinamente nuevos fenómenos de seguridad han impactado globalmente y permeado hacia Latinoamérica. Esta condición es la responsable del impulso dado para adecuar estructuras de Defensa, las que no exentas de burocracias propias de las administraciones, ha sido observada en Chile $^{19}$.

Del mismo modo, el Centro de Estudios Estratégicos del Perú, junto con el Real Instituto El Cano de Madrid, España, establecen una realidad muy similar al descrito por los investigadores de la ANEPE, postulando "...frente a este escenario, los gobiernos de América Latina han adoptado cada vez más soluciones relacionadas con el empleo de las Fuerzas Armadas en el combate al crimen organizado, considerado responsable de gran parte de la violencia en la región ${ }^{\prime 20}$. Aceptando o rechazando esta posibilidad, lo cierto es que el cerco que ha separado prolongadamente, a nuestro juicio, las actividades que realizan las fuerzas policiales de las que llevan a cabo las FF.AA. sigue estrechándose e incluso traslapándose aceleradamente.

De esta manera el terreno se presentaba fértil para profundizar en críticas ante la falta de preparación de los medios, en aquellas instancias cuando el sistema de seguridad estatal democrático ha sido superado. En efecto, durante la última década, somos testigos de la constante presión social ejercida sobre los gobiernos, quienes luego de importantes alteraciones a la seguridad, intentan modificar ciertas nociones rígidas y circunscritas a los roles y funciones de las FF.AA. en tiempo de paz.

Una mirada sobre esta realidad regional es descrita en la revista "Balance Estratégico Sudamericano: años de cambios", en cuyas páginas el lector puede confirmar la evidente preocupación regional por la renuncia de los gobiernos a tomar medidas de control con características multisectoriales, que incluyan a las FF.AA.:

La dilución de los límites entre la seguridad interna y externa invita a reflexionar respecto de la manera que los diferentes países de la región, en concordancia con el espíritu de sus ordenamientos constitucionales, han profundizado el aporte de la Defensa al esfuerzo país para enfrentar estas nuevas amenazas. No hacerlo sería abdicar de uno de los principales instrumentos de que dispone el

19 ANEPE. "Elementos políticos y estratégicos en las decisiones de política pública". En: "Colección de investigaciones", ANEPE N45, diciembre 2019. pp. 15-205.

20 CEEP-Real Instituto El Cano. "La transformación de las Fuerzas Armadas en América Latina ante el crimen organizado”. Primera edición, enero, 2019. p. 22. 
Estado para enfrentarlas. La determinación de los límites y formas de hacerlo, conciliando su cultura y ordenamiento jurídico con la fuerza de la realidad, es el desafio ${ }^{21}$.

El debate se encuentra abierto en prácticamente toda la región latinoamericana, discusión que paulatinamente ha logrado avanzar en áreas estratégicas que han superado lentamente los traumas del pasado para comenzar a conferir cuerpos legales modernos, del mismo modo concebir estructuras sustentadas en presupuestos confiables y transparentes, también diseñar nuevas estrategias bajo un marco democrático, donde las autoridades sectoriales (zorro), en comunión con los conductores estratégicos (erizo), respondan de su diseño.

En palabras del almirante Craig S. Faller (SOUTHCOM), quien exponiendo recientemente ante el Comité de Servicios Armados del Senado de los EE.UU. el pasado 30 de enero de 2020, declaró sobre aquellas preocupaciones que aquejan a Latinoamérica, "Podría decir que los desafíos conforman un círculo vicioso de amenazas, que socavan deliberadamente la estabilidad y la seguridad en la región". Reflexión que no hace más que ratificar el postulado de que los modos y modelos estratégicos se han postergado por décadas y requieren una pronta definición política.

El corolario de este apartado nos lleva nuevamente a Delmas quien fustiga la debilidad de las estructuras del Estado y, sobre esta condición, sostiene que el desajuste que se produce, entre el Estado-país y el Estado-nación, es una brecha que puede alterar a cualquier sistema de gobierno y consecuentemente afectar en la seguridad ${ }^{22}$.

En este punto se puede sostener un hallazgo de sesgo, postulando que con la enorme cantidad de estudios existentes y considerando el nivel de información que disponen las autoridades sectoriales no se ha perseverado en adecuar las estructuras de la Defensa de la manera que exige el entorno internacional y, en el cual, Latinoamérica se articula.

Esta aseveración se construye desde el ideal de paz suramericano acuñado durante más de una década, afirmación que no admitiría disensos, favoreciendo de esta manera la apertura de espacios para el crimen organizado, narcotráfico o terrorismo y que Taleb lo describe como "Cisnes Negros"23. Por tanto, cualquier manifestación referida como nuevas amenazas ha sido considerada como un imprevisto y, con el tiempo, la región se ha acostumbrado a los imprevistos o más bien a muchos cisnes negros.

\section{La naturaleza del erizo}

El "ethos" 24 que distingue la estructura de las instituciones armadas y, en lo particular,

21 ANEPE. Balance Estratégico Sudamericano 2016-2017: años de cambios. p. 73 (diciembre 2017). [En línea] [fecha de consulta 15 de junio 2020] Disponible en: <https://www.anepe.cl/wp-content/uploads/ BALANCE estrategico sudamericano.pdf $>$.

22 DELMAS. Op. Cit. pp. 162-163.

23 TALEB, Nassim. "The Black Swan: the impact of the highly improbable". Random House, Inc. 2007. p. 409. [En línea] [fecha de consulta 16 de junio 2020] Disponible en: <http://citeseerx.ist.psu.edu/viewdoc/ download?doi=10.1.1.695.4305\& $\mathrm{rep}=$ rep1\&type $=\mathrm{pdf}>$.

24 Ethos: La Real Academia Española (RAE), define como: “Conjunto de rasgos y modos de comportamiento 
las FF.AA. latinoamericanas es su auto-percepción de protectoras del Estado, condición que las instala en un sitio de privilegio para cumplir con el objetivo de resguardar a la nación y contribuir al logro del bien común ${ }^{25}$. Pudiendo admitir o disentir de esta reflexión, es evidente que el hecho de haber participado en la formación del Estado-nación les otorga un estatus cívico que les distingue por sobre otras estructuras o colectividades que fueron incorporándose luego de la progresiva maduración organizacional del Estado.

En Sudamérica este rol activo y participativo se ha mantenido en el tiempo, distinguiéndose períodos de intenso involucramiento político con la instalación de gobiernos militares, en décadas de los setenta y ochenta, hasta su retorno a los cuarteles -a partir de la década de los noventa- con el re-establecimiento de gobiernos democráticos.

Pese a todas las consecuencias que implicó su participación gubernamental, su "ethos" es asumido como una doctrina justificadora para sostener la definición de roles, funciones y misiones trascendentales en la estructura superior del Estado. Huntington sostiene que este sentimiento es propio de la existencia de una mentalidad y una ética militar que muestra signos de realismo y conservadurismo, y que fomenta reacciones que valoran por encima de todo aspecto, como la organización, la disciplina y el liderazgo ${ }^{26}$. Es en este entorno que las FF.AA., a nivel global, desarrollan una función pública que el Estado les ha otorgado y que ningún otro colectivo podría sustituir, cual es la Defensa del territorio ante agresiones, protección a la población y de esta forma contribuir a su desarrollo de forma segura, conceptualización que no hace más que validar su "ethos"27.

Respecto de las amenazas que el Estado debe distinguir, sin lugar a dudas que representa un enorme dilema dada su condición en el sistema internacional, de hecho, en nuestros días se han configurado "nuevas amenazas" que requieren ser tratadas por FF.AA. que cuenten con capacidades acordes a la naturaleza del fenómeno. Dicho en palabras de García Covarrubias "en la actualidad las definiciones del ámbito de la seguridad y defensa deben ser flexibles y tener la capacidad de entender el presente y leer el futuro, de acuerdo a las tendencias estratégicas que se van levantando en el planeta"28.

De esta manera, fenómenos que otrora fueron vistos como riesgos a la seguridad interior del Estado, hoy constituyen verdaderas amenazas y se han sumado otras que

que conforman el carácter o la identidad de una persona o una comunidad". [En línea] Disponible en:< https://dle.rae.es/?w=ethos $>$.

25 KRUIJTY, Dirk y KOONINGS, Kees. "Fuerzas Armadas y políticas en América Latina: perspectivas futuras". Iberoamericana, Nueva época, Año 2, No. 8 (diciembre de 2002), pp. 7-22. Published by: Iberoamericana Editorial Vervuert.

26 HUNTINGTON, Samuel. "The Soldier and the State". En: BARRACHINA, Carlos y RIAL, Juan. "Los Ministerios de Defensa en América Latina y las consecuencias de la multidimensionalidad de las amenazas. América Latina hoy". En: "Revista de ciencias sociales". Agosto 2006, p. 9.

27 ANEPE. "Dimensión Militar, Ethos y FF.AA. en la sociedad". Panorama de Seguridad \& Defensa N³, agosto 2020. [en línea] [fecha de consulta 12 de agosto 2020] Disponible en: <https://www.anepe.cl/ladimension-militar-ethos-y-ff-aa-en-la-sociedad/>.

28 ANEPE. "La seguridad: un asunto de Estado". Panorama de Seguridad \& Defensa N 5. (Marzo 2020). [en línea] [fecha de consulta 17 de junio 2020] Disponible en: <https://www.anepe.cl/la-seguridad-un-asunto-de-estado/>. 
La Defensa: en el dilema del zorro y el erizo

cuentan con espacio para diseminarse de manera virulenta, así migraciones, narcotráfico, tráfico de armas, terrorismo, armas biológicas, ciberataques, lucha híbrida, dominio de inteligencia artificial e impactos por calentamiento global, están eclipsando la clásica visión de posibles disputas fronterizas que se traducían en hipótesis de conflicto a las que las FF.AA. solían acudir, observándose a nivel regional que aquella clásica noción de defensa territorial se encontraría desajustada de esta realidad y de los escenarios de futuro que se conciban.

Así las cosas, la articulación de cuestiones como formación, organización, doctrina, presupuesto, planes, políticas y estrategias, entre otros aspectos, representan para las FF.AA. un especial estímulo al que se debería poner atención, porque constituyen parte de su "ethos", y en la medida que el nivel político y el sector civil de la Defensa no logre una adecuada armonía con el estratega se percibe como un desinterés hacia temas de suyo prioritarios.

Resulta oficioso señalar que las relaciones civil-militares en la región han sido objeto de escasos estudios, algunos de ellos aquí descritos, que han avanzado en tratar de medir las variables de "efectividad, eficiencia y democrático control civil" de las FF.AA., aspecto sobre cual el Bruneau coincide con Pion-Berlin, luego que presentara hallazgos muy diferentes con algunos países de Europa ${ }^{29}$.

Por otra parte, el mismo Pion-Berlin junto a Trinkunas, en otra publicación, establece a lo menos cuatro elementos que han contribuido a este "impasse" en las relaciones civiles-militares exhibiendo un margen negativo que impacta sobre el control democrático en las instituciones de la Defensa, siendo las más observables ${ }^{30}{ }^{31}$ :

- Desconfianza entre los actores, civil-militar/militar-civil.

- Baja prioridad en temas relacionados con políticas de Defensa.

- Falta de políticas de seguridad y defensa.

- Visión confusa respecto de nuevas amenazas y riesgos a la seguridad regional.

Destaca un significativo hallazgo que sustenta Piuzzi, quien mientras llevaba a cabo una investigación que comparaba realidades sudamericanas, consigna: "...en Latinoamérica, los escasos trabajos sobre Fuerzas Armadas y Sociedad se habían focalizado en su mayor parte en el estudio de las relaciones civiles militares, desde una perspectiva de la participación militar en el sistema político, centrados en gran medida en intervenciones militares y golpes de Estado"32.

29 BRUNEAU, Thomas C. "Civilians and the Military in Latin America: The Absence of Incentives. Article in Latin American Politics and Society. Op. Cit. pp. 143-160.

30 PION-BERLIN, D. y TRINKUNAS, H. "Why Politicians and Scholars Ignore Defense Policy in Latin America", Meeting of the Latin American Studies Association, San Juan, Puerto Rico. March 15-18, 2006.

31 PION-BERLIN, David. "The Defense Wisdom Deficit in Latin America: A Reply to Thomas C. Bruneau". En: "Revista Fuerzas Armadas y Sociedad", Año 20, N 1, 2013. pp. 51-62.

32 PIUZZI José M. "Fuerzas Armadas y Sociedad: Algo más que sentido común". Academia Nacional de Estudios Políticos y Estratégicos, Cuaderno de Trabajo $N^{\circ} 14,2018$. p. 5. [en línea] [fecha de consulta 17 de junio 2020] Disponible en: <https://www.anepe.cl/wp-content/uploads/Cuaderno-de-Trabajo- 
Sin duda que estos signos junto con los antecedentes previamente desarrollados en este apartado aportan antecedentes suficientes como para reconocer como sesgo en la evaluación del "democrático control civil" postulado en la tríada de Bruneau. En efecto, se omite la debida correlación de importancia a los instrumentos detallados en los cuadros $\mathrm{N}^{\circ} 2-4$ y 5 respectivamente, y que propician el camino del control y conducción civil del sector Defensa en democracia por extensos años, de esta manera se desvía el análisis original, condición que sucede en trabajos de similar ejecución observados en este ensayo, ya que se posesionan sobre contenidos que reflejan visiones políticas más allá de lo profesional o especializado que se requeriría.

A consecuencia de este ambiente conceptual, impulsado por la tríada, se le atribuye a las FF.AA. la responsabilidad de un lento progreso y distanciamiento entre el militar y el político, cuestión que inhibiría contar con una noción de una Defensa integrada, multisectorial y moderna requerida para otorgar certezas por sobre ambigüedades propias de burocracias. ¿Qué opinión tendrá el erizo sobre esta afirmación?

\section{La Defensa en el entorno del zorro}

Este apartado se inicia reflejando la opinión de Barrachina y Rial quienes afirman que la guerra contra el narcotráfico y terrorismo, iniciada por EE.UU. a partir del 2001, y luego de la presión ejercida, como "hegemon", hacia la región habría provocado una involución del proceso de democratización del sector Defensa. Entre las consecuencias más plausibles de esta situación estarían la falta de control político y la reducida participación de civiles en los ministerios de Defensa. Del mismo modo, el reconocimiento de carácter multidimensional de las amenazas a la seguridad, suscrito por la OEA el 2003, sería un error ya que ampliaba el espectro de las funciones de las FF.AA. hacia asuntos internos ${ }^{33}$.

Este tipo de afirmaciones, sin lugar a dudas, provoca nubarrones sobre las relaciones civiles-militares de la época, propiciando una discusión forzada y en sentido restrictivo. Primero, porque condiciona el relato sobre relaciones amigo-enemigo, dejando a un lado aquellos que apoyan la política de seguridad de EE.UU. y, del otro, quienes están en contra, como si aún se aplicara la mentada "Doctrina de Seguridad Nacional" que dejó significativas huellas en la región y que los mismos investigadores critican. Segundo, sitúa al elemento civil como sujeto desprovisto de poder e influencia y, prácticamente, estaría subordinado a una organización militar fuerte que no facilitaría una correspondencia de funciones. De esta manera, se desconoce todo avance hecho en diferentes ministerios de Defensa a esa fecha, salvo excepciones que demuestra el cuadro $\mathrm{N}^{\circ} 4$ la región presenta altos indicativos de gobernanza del sector:

N\%C2\%B014-2018-.pdf >.

33 BARRACHINA, Carlos y RIAL, Juan. "Los Ministerios de Defensa en América Latina y las consecuencias de la multidimensionalidad de las amenazas". En: "América latina hoy, Vol. 42". Abril 2005. [en línea] [fecha de consulta 19 de mayo de 2020] Disponible en: <file:///C:/Users/F404B 1.QUE/AppData/Local/Temp/2462$\underline{6782-1-P B . p d f}>$. 
La Defensa: en el dilema del zorro y el erizo

\section{Cuadro 4}

Procedencia de autoridades que han desempeñado la dirección del Ministerio de Defensa en países suramericanos (2005-2019)

\begin{tabular}{|l|c|c|c|c|c|}
\hline \multicolumn{1}{|c|}{ País } & $\begin{array}{c}\text { Período } \\
\mathbf{2 0 0 5}-\mathbf{9}\end{array}$ & $\begin{array}{c}\text { Período } \\
\mathbf{2 0 1 0}-\mathbf{1 4}\end{array}$ & $\begin{array}{c}\text { Período } \\
\mathbf{2 0 1 5}-\mathbf{1 9}\end{array}$ & $\begin{array}{c}\text { Dirección } \\
\text { Civil }\end{array}$ & $\begin{array}{c}\text { Dirección } \\
\text { Militar }\end{array}$ \\
\hline \hline Argentina & $\mathrm{C}$ & $\mathrm{C}$ & $\mathrm{C}$ & 14 años & 0 \\
\hline Bolivia & $\mathrm{C}$ & $\mathrm{C}$ & $\mathrm{C}$ & 14 años & 0 \\
\hline Brasil & $\mathrm{C}$ & $\mathrm{C}$ & $\mathrm{C}-\mathrm{M}$ & 12 años & $\mathbf{2}$ años \\
\hline Colombia & $\mathrm{C}$ & $\mathrm{C}$ & $\mathrm{C}$ & 14 años & 0 \\
\hline Chile & $\mathrm{C}$ & $\mathrm{C}$ & $\mathrm{C}$ & 14 años & 0 \\
\hline Ecuador & $\mathrm{C}$ & $\mathrm{C}$ & $\mathrm{C}$ & 14 años & 0 \\
\hline Paraguay & $\mathrm{C}-\mathrm{M}$ & $\mathrm{C}-\mathrm{M}$ & $\mathrm{C}-\mathrm{M}$ & 3 años & 11 años \\
\hline Perú & $\mathrm{C}-\mathrm{M}$ & $\mathrm{C}-\mathrm{M}$ & $\mathrm{C}-\mathrm{M}$ & 7 años & 7 años \\
\hline Uruguay & $\mathrm{C}$ & $\mathrm{C}$ & $\mathrm{C}$ & 14 años & \\
\hline Venezuela & $\mathrm{M}$ & $\mathrm{M}$ & $\mathrm{M}$ & 0 & 14 años \\
\hline
\end{tabular}

Fuente: elaboración propia extraída de antecedentes obtenidos de sitios oficiales y páginas web de ministerios de Defensa LATAM. (nota: $\mathbf{C}=$ Civil / $\mathbf{M}=$ Militar)

Tras tres años para que los nubarrones de incertidumbre se disiparan, el Seminario Internacional programado por el CDS-UNASUR (Quito 2009), a nuestro criterio, solo sirvió para continuar recogiendo diferentes visiones regionales y locales de las preocupaciones a la seguridad. Se destaca lo expresado en dicha oportunidad por Francisco Rojas, quien repara sobre ciertas tendencias al mantenimiento de conflictos, respaldando su afirmación por la latencia de conflictos tradicionales que tendrían su origen en disputas territoriales. Sorprende en cierta medida, ya que se separa de la idea fija de "zona de paz" de UNASUR.

Por otra parte, al referirse a las principales amenazas, sostiene que no califican como preocupaciones del sector Defensa, ya que primordialmente están vinculadas al fenómeno del crimen organizado. Del mismo modo, asevera que esta nueva dimensión requeriría, necesariamente, de un debate político para dar una adecuada respuesta. Finalmente, hace una velada crítica a los actores políticos por la ligereza de emplear las FF.AA. en estas actividades, advirtiendo que no están preparadas para este tipo de enfrentamientos ${ }^{34}$.

En consecuencia, en el seno de UNASUR el debate continuaba anclado en dos líneas de acción: la primera respecto de la coexistencia de conflictos tradicionales, aunque fuera del continente y, la segunda, la forma de abordar las nuevas amenazas circunscritas principalmente en el crimen organizado, fenómeno que debiese continuar siendo asumido por fuerzas policiales. El cuestionamiento nuevamente se reitera ¿Era la única y principal amenaza regional, o dicha instancia solo sirvió para continuar con el derrotero de aislar las

34 UNASUR-CDS. Memorias del Seminario “Modernización de los Ministerios de Defensa”. Quito, 19-20 de noviembre, 2009. pp. 11-15. [En línea] [fecha de consulta 17 de junio 2020]. Disponible en: <https:// www.academia.edu/3843447/Memorias del Seminario Modernizaci\%C3\%B3n de los Ministerios de Defensa >. 
propuestas de la Defensa de la gran discusión?

Una respuesta podría ser recogida del análisis dado por Pablo Celi ${ }^{35}$ quien a modo de "mea culpa" expresa "...la amplitud de la multidimensionalidad, con su dispersión de objetivos y dificultades de operacionalización, configuró sus propios límites políticos e institucionales. No llegó a establecer una política hemisférica de seguridad y defensa común ni definió un marco institucional unívoco".

Se insiste en que la región debería preparar una laguna en terrenos de UNASUR, para concentrar los "Cisnes Negros" que han ido anidando. Taleb también se cuestiona: ¿Por qué no reconocemos el fenómeno de los cisnes negros hasta después de que ocurran? Y como respuesta afirma "...los humanos están programados para aprender detalles cuando deberían centrarse en las generalidades. Nos concentramos en cosas que ya sabemos y una y otra vez no tenemos en cuenta lo que no sabemos" ${ }^{36}$.

En léxico ingenieril se puede aseverar que, si los cálculos de andamiajes están errados y no soportan la estructura, el resultado será, a lo menos, demoledor. En esta lógica se postula en señalar que el cálculo dado por UNASUR, en términos de Seguridad y Defensa, no soporta la estructura para enfrentar los desafíos continentales. En el inicio de estas reflexiones se reitera el iluso consenso regional de "zona de paz", escenario que se aleja crudamente de los datos; solo bastaría analizar las estadísticas de fallecidos entre el año 2000 y el 2016 para confirmar que aproximadamente 2,5 millones de personas fueron víctimas de actos criminales vinculados al narcotráfico, crimen organizado y tráfico de $\operatorname{armas}^{37}$; en consecuencia, el término debiese estar ligado a "zona de paz, con controversias", y de esta manera abordar los retos con un realismo regional.

Por otra parte, la declaración conjunta de los delegados de Nicaragua, Venezuela, Ecuador y Bolivia que desahucian, el año 2012, el Tratado Interamericano de Asistencia Recíproca (TIAR), tensiona aún más el entorno descrito. El acordar un nuevo pacto que apuesta a sustituir viejas mentiras por nuevas verdades bajo la reseña: "Nuestros países han tomado la decisión de enterrar lo que merece ser enterrado, de tirar al tacho de la basura lo que ya no sirve". De esta forma, se aboga por la existencia de nuevas instancias multilaterales, más modernas y alejadas de la Guerra Fría, enarbolando a la Alianza Bolivariana para los Pueblos de Nuestra América (ALBA), como una organización destinada a liderar las grandes reformas regionales. ¿Cuáles serían éstas?, ya que en el transcurso de su evolución se ven más sombras que luces, especialmente tras el retiro de varios países signatarios de lo que se postulaba como un ícono multilateral ${ }^{38}$. Este acto, a nuestro modo, solo agudiza la cuestión de las relaciones civiles-militares ya que ideologiza un entorno político-estratégico, de por sí complejo, y que requiere atención.

35 CELI, Pablo. "La multidimensionalidad de la seguridad nacional: retos y desafíos de la región para su implementación". IUGM, diciembre, 2015. pp. 13-28. En: <https://iugm.es/wp-content/ uploads/2016/06/2015-1325 Interiores SIN MARCAS.pdf $>$.

36 TALEB. Op. Cit. p. 2.

37 MUGGAH Robert and AGUIRRE Katherine. "Citizen security in Latin America: Facts and Figures". En: "Strategic Paper 33", april, 2018. [En línea] [fecha de consulta 17 de junio 2020] Disponible en: <https:// reliefweb.int/sites/reliefweb.int/files/resources/Citizen-Security-in-Latin-America-Facts-and-Figures.pdf>

38 BALANCE ESTRATÉGICO SUDAMERICANO. Op. Cit. pp. 36-37. 
Avanzando en nuevos entornos de incertidumbres se menciona la proyección de la dimensión de ciberseguridad. Se puede señalar que tras los buenos oficios anunciados en UNASUR (CDS-CEED), se programaron Planes de Acción (2013/2014), seminarios y otras instancias al alero de Grupos de Trabajo, y revisando los antecedentes se llega a la conclusión que el terreno aún se presenta estéril y lejos para germinar políticas multilaterales, principalmente por la renuencia que han mostrado los delegados a la idea de reunir capacidades militares en apoyo a labores de seguridad interna, malogrando una oportunidad de generar sinergia de trabajo que pudiese colaborar en la identificación de potenciales escenarios de "no guerra", muy característicos en este nuevo espacio.

La educación en materias de Seguridad y Defensa valdría para un capítulo especial, ya que continúa siendo un aspecto bastante contradictorio. Para ser concreto, quienes amparan la fábula del "Zorro y el Erizo" presentan la tesis de la prescindencia del conocimiento de civiles en temas de Defensa, sosteniendo que en altos niveles de la conducción se requiere otro tipo de asesorías, "ergo" otras competencias. De ser así, por qué el retardo de los procesos modernizadores en Defensa, o por qué no ha habido una mejor interpretación de escenarios de riesgos y amenazas, y así preparar o al menos prevenir sus efectos sobre la población.

Sobre este trascendental aspecto resultan devastadoras las reflexiones patrocinadas por Saint-Pierre, quien da cuenta de la evidente omisión generalizada sobre temas de Defensa en Latinoamérica, comprendiendo que las prioridades nacionales difieren de un sitio a otro, pero no resulta comprensible dicha ausencia por parte de la academia e injustificable por parte de la clase política. Reconociendo cierto progreso percibe que la formación de asesores y personal especialista en estos temas sigue débil ${ }^{39}$.

Años más tarde, esta misma impresión la sostienen Barrachina y Rial aseverando que la preparación de empleados de origen civil continúa siendo un problema en la región, si bien, las Academias o Institutos de Formación Superior en temas de Defensa, se posesionan como buena alternativa para lograr esta función, desafortunadamente sus aulas son ocupadas por burócratas de diferentes estamentos estatales quienes, una vez egresados, escasamente se interesan por el sector de la Defensa ${ }^{40}$.

La contingencia del COVID-19 ha desnudado las falencias de estructuras gubernamentales para enfrentar esta pandemia y habrá que esperar un tiempo para sacar las respectivas conclusiones; sin embargo, un entendido en estrategia seguramente presentaría como hipótesis si se pudo haber previsto sus catastróficas consecuencias ${ }^{41}$. El contar con capacidad y entrenamiento resulta clave para visualizar posibles situaciones de crisis o eventuales escenarios de riesgo. Al parecer es más efectivo tratar este tipo de problemas como imprevistos o "Cisnes Negros". ¿Será que los peligros reales para

39 SAINT-PIERRE, Héctor L. "Aproximación a la política de defensa en el marco histórico latinoamericano", p. 60. En: RESDAL. Control civil de las Fuerzas Armadas: fortaleciendo el papel de la asesoría parlamentaria, Buenos Aires, 2000.

40 BARRACHINA y RIAL. Op. Cit. p. 13.

41 MOLINER, Juan A. “¿Sirven para algo las estrategias? Reflexiones a cuenta del Covid-19”. En: “Global Strategy". [en línea] [fecha de consulta 17 de junio 2020] Disponible en: <https://global-strategy.org/ sirven-para-algo-las-estrategias-reflexiones-a-cuenta-del-covid-19/>. 
los cuales se establecieron paradigmas tradicionales ya no están funcionando? PionBerlin responde a estas dudas como "la falta de interés del estamento civil por temas de Defensa"42.

Sobre este particular y grave escenario pandémico, al cual tiene a Chile y muchos países sumidos en controlar la crisis sanitaria, las palabras de Heraldo Muñoz sirven de corolario magistral para reconocer la falta de preparación en temas estratégicos. De esta manera, el excanciller chileno aboga por la creación de una Oficina de Asuntos Estratégicos de carácter multidisciplinario, que reúna expertos del mejor nivel analítico, con experiencia y contactos internacionales para proyectar escenarios de riesgos y proponer acciones frente a las amenazas emergentes y los retos a la seguridad nacional en el siglo XXI. Respecto del perfil de los profesionales destacan expertos en psicología, ciencia política, economía, defensa, biología, medicina, y otras disciplinas, y así diseñar un futuro ${ }^{43}$, entendiendo que estos transitan entre lo posible, deseable o factible.

En este contexto, se ha fustigado extensamente la concepción de "Seguridad Nacional" acuñada en período de Guerra Fría, ya que el auspicio de EE.UU. indisponía las nuevas concepciones nacidas con el retorno a la democracia de muchos países en la región. Lo paradójico es que en sentido opuesto se intentó avanzar en una "Escuela Suramericana de Defensa (2014)", cuyo propósito sería "capacitar a los civiles y militares de toda la región en materia de seguridad nacional y regional a nivel político-estratégico", su resultado es conocido y la iniciativa oscila en programas de reducida relevancia auspiciada por resabios de UNASUR.

¿Cuáles serían los argumentos de los signatarios del ALBA para organizar una Escuela de Defensa con rasgos "antiimperialistas"? Seguramente el lector podrá extraer sus propias conclusiones. Estas significativas señales son constantes que no se ven reflejadas en los análisis de los autores seleccionados, conscientes o inconscientes de ellas constituye un sesgo, ya que sitúa la evaluación desde la perspectiva de FF.AA. que son afines a EE.UU. o aquellas que no lo son, desvirtuando la variable original de "democrático control civil" sustentada en las relaciones civiles-militares y que abriga un multilateralismo inclusivo.

\section{Nuevos escenarios para el zorro y el erizo}

Sin desmerecer las capacidades propias que poseen diferentes organizaciones y estructuras estatales para gestionar crisis, convengamos que las FF.AA. poseen vasta experiencia para estar sometidas a situaciones de estrés, tanto en tierra, mar y aire. Estas capacidades se logran tras años de preparación y entrenamiento, constituyendo una herramienta estatal útil para enfrentar períodos complejos. De esta manera se debe reconocer que cuentan con un grupo de personas que, junto con dedicarse a planificar cuestiones genéricas y cercanas a su función, también se especializan en planos más particulares destinados al sostenimiento del combate. Entre dichas capacidades se pueden

42 PION-BERLIN. Op. Cit. pp. 51-62.

43 MUÑOZ, Heraldo. Excanciller de Chile, "Chile ante los Coronavirus del futuro". En Diario El Mercurio, 8 de abril 2020. [en línea] [fecha de consulta 17 de junio 2020] Disponible en: <https://www.elmercurio.com/ blogs/2020/04/08/77809/Chile-ante-los-coronavirus-del-futuro.aspx> 
observar áreas de logística, ingeniería, salud y transporte que evidentemente revisten similitudes en organizaciones estatales civiles y organismos privados.

Lo anterior posee un elemento central para el buen éxito de su cometido: la planificación. Por esta razón, fundamental sería contar con buenos planificadores que produzcan un buen plan y que este funcione en el terreno (realista), en circunstancias extremas, complejas y difíciles. En este entorno aplica el lograr una transferencia de conocimientos y experiencia en ambas direcciones, desde el militar al civil y viceversa, a fin de sincronizar el trabajo y familiarizar códigos.

Sostengamos que el estadio de comprensión del político y del estratega se encuentra abrazado por un entorno global que ha cambiado dramáticamente desde el término de la Guerra Fría, agudizado con la declarada Guerra contra el Terrorismo, post 11 de septiembre del 2001, y ampliado regionalmente con la Declaración de Seguridad de la OEA del 2003. Compartiendo esta visión, se puede postular que el fenómeno del conflicto transformó las tradicionales nociones de riesgos y amenazas estatales, augurando que serán más complejos. Esta configuración implica contar con capacidades humanas para diseñar planes y estrategias que visualicen nuevos escenarios donde todos los instrumentos estatales estén en sintonía con realidades de futuro y no del pasado.

Es aquí donde Buzán, Karlor, Bartolomé, Griffiths, Pion-Berlin y hasta el mismo Bruneau coinciden en sus preocupaciones sobre cómo resolver los complejos acertijos que están imponiendo ciertos fenómenos que otrora se presentaban como riesgos y que con el trascurrir de la globalización han mutado en manifestadas amenazas. Tal ha sido el impacto de estas manifestaciones, que varios gobiernos regionales han tomado la decisión de recurrir al empleo de los instrumentos de la Defensa para enfrentarlas, ya sea vía la excepción o cotidianamente al estar formalizado en políticas sectoriales.

La última revista "Balance Estratégico Sudamericano: paz con controversias", nuevamente aborda dicha preocupación regional, esta vez cuestionando si el escaso avance en estas materias es limitado, temporal y si se contará con la suficiente preparación de las FF.AA., concluyendo:

En el Cono Sur, entre 2018 y 2019, Argentina, Chile y Uruguay cedieron por primera vez al empleo de las FF.AA. en tareas contra el Crimen Transnacional, pero parecieran estar lejos de los esquemas multilaterales. El temor de que no se mantenga nítida la línea divisoria entre la seguridad interior y exterior, parece haberse diluido ante la necesidad de retomar el control de áreas cooptadas por el efecto globo del narcotráfico y de sus rutas. Queda en discusión si pasarán a ser estas funciones primarias o serán siempre secundarias; si complejizarán la autonomía institucional, o bien, si la preparación de las fuerzas es la adecuada ${ }^{44}$.

Se puede establecer que las "nuevas amenazas" transitan por la vía política,

44 ANEPE. Balance Estratégico Americano 2018-2019: paz con controversias. p. 83 (Diciembre 2017). [en línea] [fecha de consulta 17 de junio 2020] Disponible en: <https://www.anepe.cl/wp-content/uploads/ BALANCE 2018-2019.pdf >. 
económica, diplomática, cultural, psicológica y militar, además en dimensiones terrestre, marítima, aérea, espacio ultraterrestre, ciberespacial, biológica y tecnológica, y la interacción entre todos estos vectores ha hecho que sea más difícil alcanzar un efectivo grado de comprensión, para que sea interpretado tanto por el político como el estratega, cerniéndose en un limbo de incertidumbres que finalmente diluye el rol de las autoridades que debiesen abrigar la responsabilidad de protección estatal.

Mientras, el avance en redefiniciones y nuevas conceptualizaciones sobre fenómenos mundiales y regionales ha continuado con cierta regularidad. Hoy día no resulta difícil encontrarse con estudios que nos ilustran sobre guerras de 4ta. generación, guerra híbrida, guerra irrestricta, guerra cibernética, guerra espacial, armas autónomas letales, el desarrollo de inteligencia artificial, la nanotecnología y la biología molecular, entre otras dimensiones, que debiesen encender las alertas para el diseño de la próxima Defensa. Sobre estas complejidades debe considerarse la latencia de los actuales fenómenos del narcotráfico, crimen organizado y terrorismo, y de esta manera dotar a las FF.AA. de suficiente preparación y estructura.

Finalmente, sobrellevar la responsabilidad de participar en operaciones militares distintas a la guerra ${ }^{45}$ a través de operaciones de paz o bien en funciones vinculadas con la gestión de catástrofes o desastres, actividades circunscritas en la lógica de contribución a la sociedad nacional e internacional, demuestra que son tareas disímiles y complejas que merecen un laborioso tiempo de perfeccionamiento, y donde las FF.AA. poseen un potencial considerable y altamente valorado ${ }^{46}$.

Lo preocupante es que la brecha que separa ambas realidades, la del zorro y del erizo, se mantiene con el tiempo, ya que la solución no pasa exclusivamente por la "asignación de recursos", "la eficiencia" o el "control democrático" de la estructura de Defensa como se ha pregonado en publicaciones de algunos autores mencionados en este estudio. En efecto, mientras se continúe con un sesgo analítico sobre la falta de conocimiento específico-militar en niveles de decisión política para abordar las nuevas lógicas que impactan en Seguridad y Defensa estatal, más temprano que tarde se cobrará la factura a las soluciones cortoplacistas por las que, peligrosamente, han transitado autoridades de la región.

Recurrente es señalar la reducida participación de los diferentes estamentos estatales en la formulación de políticas, asignación de presupuestos o bien el control de las misiones asignadas a las FF.AA., sin embargo, el resultado de un trabajo crítico en esta materia demuestra lo contrario, ya que en general existen instancias que permiten a los poderes democráticos del Estado ejercer sus atribuciones (cuadro $\mathrm{N}^{\circ} 5$ ), en consecuencia, el conocimiento y responsabilidad en materias de Defensa resulta relevante para estos niveles de decisión. Si es eficiente o no, es materia de otra discusión.

45 BAHAMONDES, Osvaldo. "Empleo de la FF.AA. en operaciones militares distintas de la guerra". ANEPE. Cuaderno de Trabajo $N^{\circ} 1 / 2016$, enero, 2016. [en línea] [fecha de consulta 17 de junio 2020] Disponible en: <https://www.anepe.cl/wp-content/uploads/cuaderno-2016-N\%C2\%BA01.pdf >.

46 ONU. Importante participación de Latinoamérica en Fuerzas de Paz de la ONU. ONU Noticias. 29 de mayo de 2013. [en línea] [fecha de consulta 17 de junio 2020] Disponible en: <https://news.un.org/es/ story/2013/05/1273131 >. 
La Defensa: en el dilema del zorro y el erizo

\section{Cuadro 5}

Atribuciones de los poderes estatales en materias de Seguridad y Defensa

\begin{tabular}{|l|l|l|l||}
\hline PARTICIPACIÓN & EJECUTIVO & LEGISLATIVO & JUDICIAL \\
\hline \hline $\begin{array}{l}\text { En política de } \\
\text { Seguridad } \\
\text { Defensa }\end{array}$ & $\begin{array}{l}\text { Define la política } \\
\text { sectorial }\end{array}$ & $\begin{array}{l}\text { Aprueba y } \\
\text { conceptualiza }\end{array}$ & $\begin{array}{l}\text { Interviene } \\
\text { parcialmente en } \\
\text { algunos países }\end{array}$ \\
\hline En presupuesto & $\begin{array}{l}\text { Define y propone } \\
\text { presupuesto }\end{array}$ & Aprueba presupuesto & $\begin{array}{l}\text { Sanciona infracciones } \\
\text { y delitos }\end{array}$ \\
\hline En adquisiciones & $\begin{array}{l}\text { Establece proyectos de } \\
\text { adquisición }\end{array}$ & $\begin{array}{l}\text { Debate y aprueba } \\
\text { proyectos de } \\
\text { adquisición }\end{array}$ & $\begin{array}{l}\text { Juzga la legalidad } \\
\text { de las acciones y } \\
\text { violaciones legales }\end{array}$ \\
\hline
\end{tabular}

Fuente: Resdal 2016, “Control civil de las FF.AA. latinoamericanas. p. 66.

Disponible en: https://www.resdal.org/libros/Archivo/libro-cajina-castro-tibiletti.pdf

\section{Retos para el zorro y el erizo}

Sin lugar a dudas que la prioridad debería estar focalizada en educación y formación de civiles y militares en temas de Seguridad y Defensa. Al parecer no estaba tan alejada de esta realidad la Junta Interamericana de Defensa, organismo que a través del Colegio Interamericano de Defensa posee la estructura necesaria para lograr la tan anhelada preparación, alejando mitos sobre añejas nociones de "Seguridad Nacional" que abrazaban ideologías en otros contextos mundiales.

Transformar la fábula del "Zorro y el Erizo" en una oportunidad y así orientarse a tender puentes por sobre la construcción de murallas entre funciones tan fundamentales como son la Seguridad y Defensa, especialmente en una región que cambió las lógicas de relaciones entre civiles y militares hace décadas. Para avanzar en este propósito se requiere mancomunar esfuerzos para hacer frente a los fenómenos multidimensionales o híbridos, entorno que se aleja del debate aislacionista o reduccionista que durante años ha perseverado en disponer a la Defensa en una esquina y la Seguridad en otra.

Un cambio cultural en temas de Seguridad y Defensa, si bien requiere transitar por la subordinación de dichas funciones al poder civil, también exhorta a las autoridades a avanzar en fórmulas de cómo plantear un eficiente y efectivo "control democrático". El comenzar por establecer una nueva forma de socializar la temática a través del "liderazgo civil y estratégico" en Defensa sería una excelente fórmula, ello considerando que este particular ambiente exige conocer en profundidad el "ethos" institucional-organizacional para construir una arquitectura sintonizada con los intereses estatales por sobre las administraciones de turno.

Frente a un escenario de conflicto híbrido se requiere desarrollar capacidades diferentes a las comúnmente conocidas, advirtiendo la necesidad de integrar asesores y especialistas con avanzada formación en Seguridad y Defensa que permitan brindar productos de valor en los niveles de decisión pertinentes. Del mismo modo, requerirá contar con una estructura de inteligencia estatal que reúna características de planificación y ejecución con alcance multiagencial. Este ambiente implica contribuir a un Sistema 
de Inteligencia que, coordinadamente, opere con todas las instituciones de Seguridad y Defensa cuando les sea requerido.

Las dimensiones de desarrollo tecnológico, así como del ciberespacio, han demostrado la existencia de brechas de conocimiento considerables, grietas que las agencias estatales deben cerrar prontamente y así evitar quedar rezagados en el empleo de nuevas tecnologías o exponerse a ataques a sus infraestructuras críticas. Este campo debiese estar interconectado con la inteligencia y así fortalecer las tramas defensivas que sean previstas bajo la "salvaguardia" de una renovada Seguridad Nacional.

En resumen, contar con una Defensa con "capacidades estratégicas modernas" requiere del diseño de una hoja de ruta de largo plazo, la que debiese estar sostenida en un plan maestro que integre una infinidad de variables, entre las más importantes: objetivos estratégicos, estructura organizacional y funcional, personal calificado, medios sofisticados, presupuesto y control eficiente de estos. Renunciar a ello es otorgar espacio para recriminaciones "de no haber hecho lo correspondiente cuando se pudo".

\section{Conclusiones}

Las diferentes administraciones de la región suramericana, como en gran parte del Continente Americano, fueron adaptando y modificando las estructuras de Seguridad y Defensa acorde a los cambios que el entorno internacional presentaba post Guerra Fría. Este escenario comenzó a romper, paulatinamente, los tradicionales paradigmas que se sostenían en torno a la Seguridad y Defensa estatal. El beneplácito otorgado a la Declaración de Seguridad de las Américas, así como a una gran cantidad de iniciativas posteriores, que incluyen las nociones de UNASUR en estas materias, impulsó a la academia a evaluar, aunque restringidamente, la función Defensa y, particularmente, a las FF.AA. en el ejercicio de nuevos roles y funciones.

Destaca en este tipo de evaluaciones la tríada de Bruneau, sostenida por otros investigadores, que han postulado evaluar tres elementos centrales que dilucidarían la efectiva transformación que se pretendía en el sector de la Defensa. Para ello, se establecen las variables "democrático control civil", "efectividad" y "eficiencia" en un entorno de relaciones civiles-militares.

Este ensayo postuló a identificar factores que revelaran la presencia de "sesgos" que han contribuido a distorsionar las evaluaciones de diferentes estudios y que pueden resumirse en:

- Luego de más de dos décadas de gobiernos democráticos, salvo un par de excepciones, aún se percibe una carga política-ideológica para analizar las relaciones civiles-militares. Esta observación se sostiene en la velada crítica que se hace al instrumento militar, atribuyéndole la mayor responsabilidad por el poco avance, e incluso retroceso de las transformaciones que, en democracia, se requerían para otorgar gobernabilidad del sector Defensa. El "sesgo de analogía del pasado" es recurrir a la comparación del comportamiento de las FF.AA. en dictaduras o gobiernos autoritarios para proyectar una conducta similar en democracia, es decir, 
se da por sentado que ciertos hechos del pasado son asimilables a las situaciones actuales reforzando así ideas preconcebidas.

- Un "sesgo de comprobación" es haber omitido antecedentes de evaluaciones del grado de conocimiento que ha mostrado el denominado "sector civil" sobre la función Defensa. Esta evidencia se ha transformado en el "talón de Aquiles" de los estudios que evitan la discusión y la centran en sopesar porcentajes de participación de civiles en los respectivos ministerios, como elementos de cuotas de representación, lo que no refleja grado de conocimiento en sí mismo.

- Del mismo modo, se ha recurrido a la falta de participación de otros órganos del Estado en temas tan importantes como el desarrollo de políticas, asignación presupuestaria y fiscalización. El "sesgo de efecto marco" se refleja en el instante que se afirma un postulado y no permite cotejar información sobre la efectiva concurrencia del Ejecutivo, Congreso y otros agentes estatales que, en gran parte de la región, cuentan con facultades propias de control y participación. La eficiencia o eficacia del aparato estatal en la fiscalización de sus cometidos no es observado. Persiste la idea de comparar gastos en Defensa, adquisiciones y procesos sin contar con una evaluación que integre la contribución a la paz y seguridad internacional (Disuasión).

- $\quad$ Por otra parte, la efectividad y eficiencia en el uso de recursos en operaciones distintas a la guerra, como OPAZ, ayuda a la comunidad en situaciones de emergencias, desastres y/o catástrofes, prácticamente es inadvertido. Sin embargo, al momento de cruzar datos de asignaciones, adquisiciones y transparencia, se hace en función del rol bélico; de esta manera se cuestiona lo oneroso que resultan las adquisiciones, para conflictos que estarían invisibles. Este "sesgo de correlación ilusoria" se presenta al omitir información y relacionar hechos de por sí distintos, prescindiendo de una valoración sobre la multifuncionalidad o polivalencia de los mismos instrumentos bélicos, y que requieren ser ponderados como herramientas de apoyo civil.

Finalmente, se puede afirmar que en los últimos veinte años, las relaciones civilesmilitares en la región han mostrado diferentes grados de madurez, lo que ha condicionado el ejercicio de gobernabilidad del sector. Ello ha obligado al "Zorro y Erizo" a perseverar para alcanzar un mayor entendimiento, principalmente para asumir tareas en un mundo y región que cambió sus tradicionales roles y funciones. En este contexto, se necesita que la función Defensa, e instrumentos que la conforman, estén sintonizados con el futuro evitando caer en "sesgos cognitivos" que se han evidenciado en diferentes estudios que fueron seleccionados para este ensayo. 


\section{REFERENCIAS BIBLIOGRÁFICAS}

ANEPE. Balance Estratégico Sudamericano 2016-2017: años de cambios. En: https://www. anepe.cl/wp-content/uploads/BALANCE estrategico sudamericano.pdf

ANEPE. Balance Estratégico Sudamericano 2018-2019: paz con controversias. En: https:// www.anepe.cl/wp-content/uploads/BALANCE 2018-2019.pdf

ANEPE. Antecedentes para el debate acerca de una estrategia de seguridad nacional. Colección de investigaciones, ANEPE N²5, diciembre 2019.

ANEPE. Panorama de Seguridad y Defensa N ${ }^{\circ}$ 5. "La seguridad: un asunto de Estado". (marzo 2020). En: https://www.anepe.cl/la-seguridad-un-asunto-de-estado/

ANEPE. Panorama de Seguridad y Defensa $N^{\circ} 3$. "Dimensión Militar, Ethos y FF.AA. en la sociedad". (agosto 2020). En: https://www.anepe.cl/la-dimension-militar-ethos-yff-aa-en-la-sociedad/

ARTEAGA, F. y FOJÓN, E. "El Planeamiento de la Política de Defensa y Seguridad de España". Instituto Universitario “General Gutiérrez Mellado" (UNED), Madrid, 2007.

BAHAMONDES, Osvaldo. "Empleo de la FF.AA. en operaciones militares distintas de la guerra". Cuaderno de Trabajo N 1/2016. Disponible en: https://www.anepe.cl/wpcontent/uploads/cuaderno-2016-N\%C2\%BA01.pdf.

BARTOLOMÉ, Mariano C. "La Seguridad Internacional en el Siglo XXI, más allá de Westfalia y Clausewitz". Colección Investigaciones ANEPE №14, septiembre 2006.

BARRACHINA, Carlos y RIAL, Juan. "Los Ministerios de Defensa en América Latina y las consecuencias de la multidimensionalidad de las amenazas". América latina hoy: Revista de ciencias sociales. Agosto 2006.

BATTAGLINO, Jorge. "La evolución de la zona de paz sudamericana". Serie de documentos de trabajo No 12, Escuela de Defensa Nacional. Buenos Aires, Argentina, 2012. Disponible en:

https://www.academia.edu/5778755/La_evoluci\%C3\%B3n_de la zona_de_paz_sudamericana

BRUNEAU, Thomas C. "Civil-Military Relations in Latin America: The Hedgehog and the Fox Revisited". Revista Fuerzas Armadas y Sociedad, Año 19, № 1-2, 2005.

BRUNEAU, Thomas C. y GOETZE, Richard B. "Las relaciones civil-militares en Latinoamérica”. Military Review, Sep-Oct. 2006.

BRUNEAU, Thomas C. "Civilians and the Military in Latin America: The Absence of Incentives". Article in Latin American Politics and Society, october 2006.

BUZAN, B., WAEVER, O., DE WILDE, O. "Security: A new framework for analysis". Boulder, 
La Defensa: en el dilema del zorro y el erizo

Lynne Rienner Publisher, 1998.

CELI, Pablo. "La multidimensionalidad de la seguridad nacional: retos y desafíos de la región para su implementación”. IUGM, diciembre, 2015.

CEEP-Real Instituto El Cano. "La transformación de las Fuerzas Armadas en América Latina ante el crimen organizado". Primera edición, enero, 2019.

DEFESA. Revista Brasileira de Estudios de Defesa, Vol. 4, N ${ }^{\circ} 2$, julho/dezembro, 2017. https://rbed.abedef.org/rbed/issue/viewFile/2977/410

DELMAS, Filippe. "El Brillante Porvenir de la Guerra". Editorial Andrés Bello. Santiago, 1996.

GARCÍA, C. Jaime. "Liderazgo Estratégico en Defensa". Security and Defense Studies Review, Vol. 12, N 1 \& 2, 2011.

GONZÁLEZ, Juan Guyer. "Revista Brasileira de Estudios de Defesa”. Vol. 4, n², 2017. En: https://rbed.abedef.org/rbed/issue/viewFile/2977/410

GRIFFITHS, S. John. "Teoría de la Seguridad y Defensa en el Continente Americano. Análisis de los casos de EE.UU. de América, Perú y Chile". RIL Editores, 2011.

HOFFMANN, R. "Conflict in the 21st Century: The Rise of Hybrid Wars". 2007. Disponible en:

https://www.potomacinstitute.org/images/stories/publications/potomac hybridwar 0108.pdf

HUNTINGTON, Samuel. "The Soldier and the State". En: BARRACHINA, Carlos y RIAL, Juan. Los Ministerios de Defensa en América Latina y las consecuencias de la multidimensionalidad de las amenazas. América Latina hoy: Revista de ciencias sociales. Agosto 2006.

KAHNEMAN, Daniel. “Pensar Rápido, Pensar Despacio”. Le Libros. 2012.

KRUIJTY, Dirk y KOONINGS, Kees. "Fuerzas Armadas y políticas en América Latina: perspectivas futuras". Iberoamericana, Nueva época, Año 2, No. 8 (diciembre de 2002)

MOLINER, Juan A. “¿Sirven para algo las estrategias? Reflexiones a cuenta del Covid-19”. Disponible en:

https://global-strategy.org/sirven-para-algo-las-estrategias-reflexiones-a-cuentadel-covid-19/

MUGGAH, Robert and AGUIRRE, Katherine. "Citizen security in Latin America: Facts and Figures". Strategic Paper 33. April, 2018. En: https://reliefweb.int/sites/reliefweb. int/files/resources/Citizen-Security-in-Latin-America-Facts-and-Figures.pdf 
MUÑOZ, Heraldo. "Chile ante los Coronavirus del futuro". En Diario El Mercurio, 8 de abril de 2020. Disponible en:

https://www.elmercurio.com/blogs/2020/04/08/77809/Chile-ante-loscoronavirus-del-futuro.aspx

ONU. "Importante participación de Latinoamérica en Fuerzas de Paz de la ONU". ONU Noticias. 29 de mayo de 2013. [en línea] Disponible en: https://news.un.org/es/story/2013/05/1273131

PION-BERLIN, David. "Political management of the military in Latin America", Military Review, 2005.

PION-BERLIN D., TRINKUNAS H., "Why Politicians and Scholars Ignore Defense Policy in Latin America", Meeting of the Latin American Studies Association, San Juan, Puerto Rico. March 15-18, 2006.

PION-BERLIN, David. "The Defense Wisdom Deficit in Latin America: A Reply to Thomas C. Bruneau". Revista Fuerzas Armadas y Sociedad, Año 20, N 1, 2013.

PIUZZI José M. "Fuerzas Armadas y Sociedad: Algo más que sentido común". Academia Nacional de Estudios Políticos y Estratégicos, Cuaderno de Trabajo N²14, 2018.

QUEIROLO, Fulvio. "Fundamentos para fortalecer la Gobernabilidad". Revista Política y Estrategia, № 132, 2018.

RESDAL 2016, "Control civil de las FF.AA. Latinoamericanas". Disponible en: https://www. resdal.org/libros/Archivo/libro-cajina-castro-tibiletti.pdf

SAINT-PIERRE, Héctor L. "Aproximación a la política de defensa en el marco histórico latinoamericano". RESDAL. Buenos Aires, 2000.

SHORT, Clare. Citada por Mark Sedra en: "Security Sector Reform 101". CIGI. April 2010, p. 3. Disponible en: https://www.cigionline.org/sites/default/files/ssr 101 final april 27.pdf

TALEB, Nassim. "The Black Swan: the impact of the highly improbable". Random House, Inc. 2007. En: http://citeseerx.ist.psu.edu/viewdoc/ download?doi=10.1.1.695.4305\&rep=rep1\&type $=$ pdf

UNASUR-CDS. Memorias del Seminario "Modernización de los Ministerios de Defensa". Quito, 19-20 de noviembre, 2009. En:

https://www.academia.edu/3843447/Memorias del Seminario Modernizaci\%C3\%B3n de los Ministerios de Defensa 